\title{
AOR
}

Selected Papers of \#AoIR2020:

The 22nd Annual Conference of the Association of Internet Researchers Virtual Event / 13-16 Oct 2021

\section{'IT'S MY FAULT FOR POSTING IN THE FIRST PLACE': HOW INDIVIDUAL RESPONSIBILITY AND SELF-BLAME ARE SUSTAINED AND INTERNALIZED}

\author{
Tony Liao \\ University of Houston \\ Haley Fite \\ University of Cincinnati

\section{Introduction}

With each instance of data breaches, corporate misuse of data, and advanced tracking programs, users are confronted with how much to continue engaging with these platforms, how to improve them, and where responsibility lies (Hargittai \& Marwick, 2016; Barth \& de Jong, 2017). After every event, there is often condemnation of the companies, but some of the blame inevitably falls on users for having trusted these companies, voluntarily posted, and turned over their information in the first place (Fiesler \& Hallinan, 2018). These messages can also contribute to a phenomenon known as 'breach fatigue,' in which people grow weary of continual privacy encroachments (Choi, Park, \& Jung, 2018).

This study attempts to explore these discourses of individual responsibility and selfblame. Using the case of algorithmically generated personality profiles, this study showed people a real-life example of data expectations being violated. By exploring their rationales and responses to these profiles, this study builds on our understanding of how people perceive algorithms, who they blame for these encroachments, how blame is internalized, and what that process might tell us about data policy.

\section{Self-Blame and Individual Responsibility as Dominant Discourses}

One avenue of research has been to examine how people react to privacy violations, or do not react in some instances. Known as the 'privacy paradox,' there has been a welldocumented disconnect between stated attitudes about privacy and actual protection behaviors (Barth \& de Jon, 2017; Debatin et al., 2009). Rather than motivate heightened protection, some researchers have found that stories of continual algorithmic intrusions can lead to 'digital resignation,' a begrudging acceptance of tracking, algorithms and 
data collection (Draper \& Turow, 2019). Thus, many believe that there is nothing they can do to effectively manage their personal information on the internet (Acquisti, et al., 2006; Hargittai \& Marwick, 2016). Even the literature on digital non-use and quitting as a solution has found that it is difficult to maintain, assumes that people know the source of data misuse, and is more complicated than a dichotomous yes/no view as far as use (Baumer et al., 2013).

As this research makes apparent, there are complicated rationalizations and compromises happening when it comes to digital privacy, as individuals navigate the space and engage in a series of trade-offs, defense mechanisms, and cognitive dissonance (Draper \& Turow, 2019; Fiesler \& Hallinan, 2018). This study aims to explore these issues using a real-world case where data was taken from participant's social media sites and entered into an unknown personality detection algorithm.

Founded in 2015, CrystalKnows automatically generates personality profiles for certain individuals through an algorithm that captures and processes public data online. Often created without their explicit consent, the resulting profile includes a set of personality indicators as well as recommendations for how to communicate and interact with this person (see Figure 1). To which we ask the following research questions:

RQ1: Where will individuals place the blame when confronted with an unidentified personality detection algorithm using unknown data sources that they did not explicitly consent to?

RQ2: What do people's rationalizations about personality detection algorithms tell us about the data privacy environment?

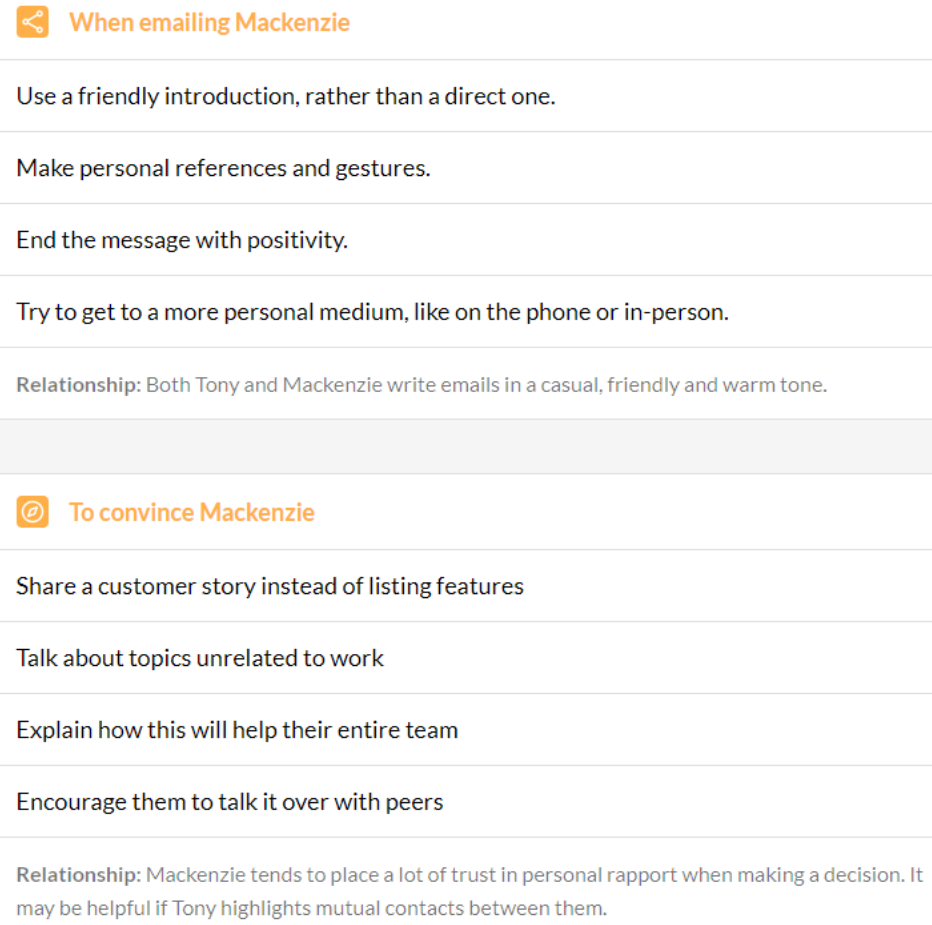




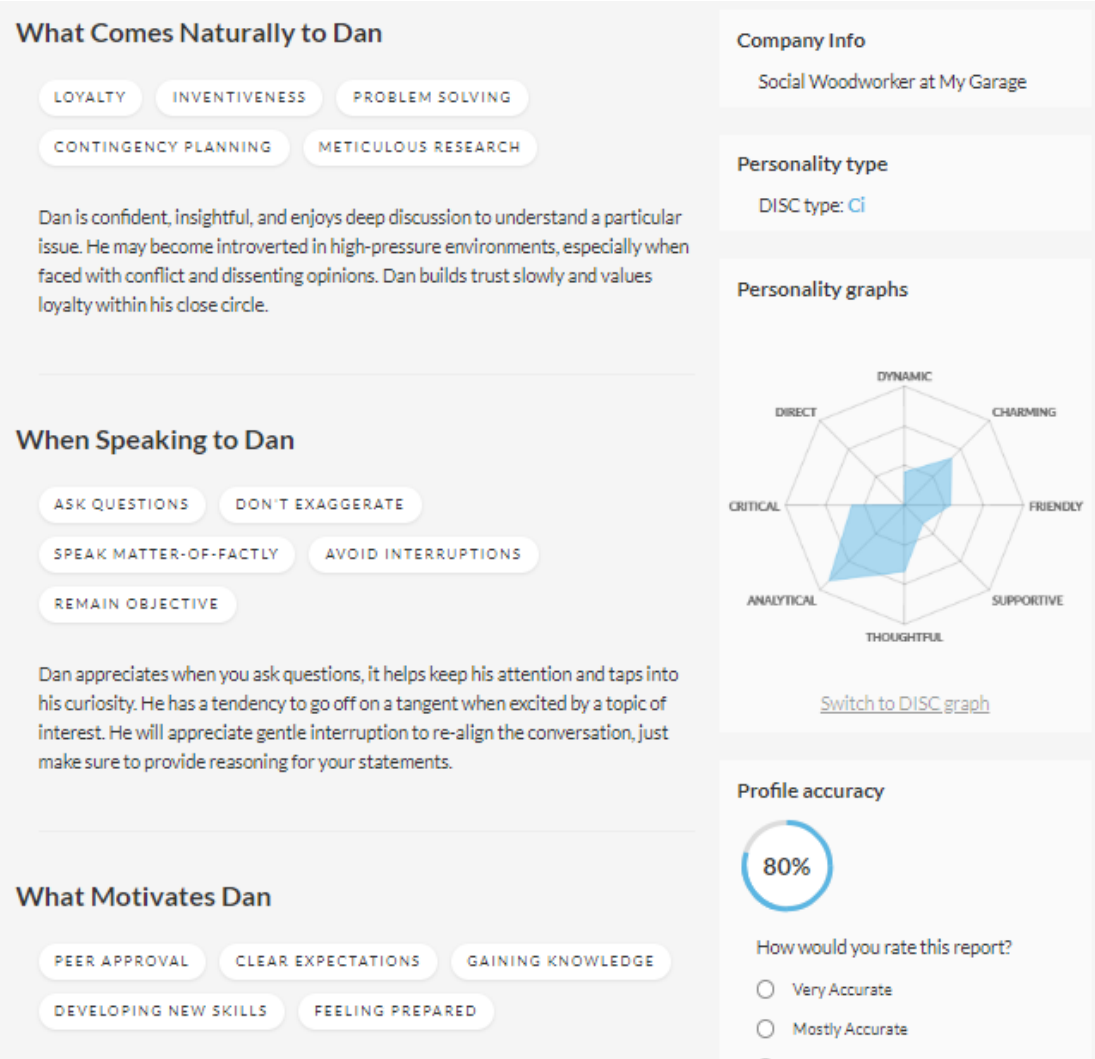

(Figure 1 - CrystalKnows Profiles)

\section{Methods}

Participants were recruited at a university in the Midwest United States. We received consent to search their names in the CrystalKnows database. Only participants who had a pre-existing profile were invited to participate. They reviewed their personality profiles before participating in a semi-structured interview about their perceptions and reactions to the algorithm. Interviews $(\mathrm{N}=37)$ were audio-recorded and coded using the data analysis program Dedoose.

\section{Findings}

RQ1: Despite not knowing anything about the company or the algorithm, self-blame was a common theme in people's responses, with various rationales.

\section{Consent Ambiguity}

Because people did not know which platform the data was coming from, they had a difficult time knowing how the profile was generated. One common response that people gave was that they "probably consented to this when they signed up for $X$ platform and didn't realize it." 
While people came up with several theories for how the algorithm operated, the only thing they knew for certain was that they were in the system, which meant that they "probably posted something where I shouldn't have." The breadth of possibilities left them uncertain and prone to speculating about their own responsibility.

\section{Presumption of Algorithmic Objectivity}

Although they did not know about Crystal beforehand, the presumption that algorithms are neutral, objective, reflections of activity, was common in people's responses. If their profile contained certain recommendations, then they must have done something to trigger it, because the "it is only showing you what you are like online."

RQ2: The rationalization of self-blame was also prevalent because the breach had already happened, which contributed to several responses.

\section{Resignation}

Being shown their profiles caused some to conclude that because this was already possible and they did not know about it, that "it is never going to stop."

\section{Quitting as an insufficient All-or-Nothing Alternative}

Not knowing the data sources that generated the profiles also rendered quitting an unrealistic option: "What am I going to do, stop using the internet?"

\section{Discussion}

This study found that even in the case of CrystalKnows, users are quick to return to an individual responsibility frame. For a variety of reasons, users internalize the discourse that blames individuals for not taking the proper precautions and for using a platform or service in the first place (Fiesler \& Hallinan, 2018). These layers of rationalization help deepen our understanding of self-blame, where it comes from, and how it leads to a lose-lose either or dilemma: accept the platform or opt-out of its use entirely. In the case of opting out, that places all of the onus onto an individual's choice, although the reality is that the power online platforms hold in terms of ubiquity, size and limited market competition hinder attempts at collective action and change (Draper \& Turow, 2019).

\section{Conclusion}

For all of the policy solutions to the digital tracking/algorithm environment that try to regulate data actors, individual responsibility and self-blame are powerful frames that have been internalized by users. One key challenge will be to break through that discourse, such that the initial act of posting justifies any subsequent action done unto the user and their data. Understanding the sources of self-blame and how deep it runs is an important step to interrogating and refuting some of these assumptions to make broader reforms possible. 


\section{References}

Acquisti, A., Friedman, A., \& Telang, R. (2006). Is there a cost to privacy breaches? An event study. ICIS 2006 Proceedings, 94.

Barth, S., \& de Jong, M. D. T. (2017). The privacy paradox - Investigating discrepancies between expressed privacy concerns and actual online behavior - A systematic literature review. Telematics and Informatics, 34(7), 1038-1058. https://doi.org/10.1016/j.tele.2017.04.013

Baumer, E. P., Adams, P., Khovanskaya, V. D., Liao, T. C., Smith, M. E., Schwanda Sosik, V., \& Williams, K. (2013). Limiting, leaving, and (re) lapsing: an exploration of Facebook non-use practices and experiences. In Proceedings of the SIGCHI Conference on Human Factors in Computing Systems, 3257-3266. https://doi.org/10.1145/2470654.2466446

Choi, H., Park, J., \& Jung, Y. (2018). The role of privacy fatigue in online privacy behavior. Computers in Human Behavior, 81, 42-51. https://doi.org/10.1016/j.chb.2017.12.001

Debatin, B., Lovejoy, J. P., Horn, A. K., \& Hughes, B. N. (2009). Facebook and online privacy: Attitudes, behaviors, and unintended consequences. Journal of ComputerMediated Communication, 15(1), 83-108. https://doi.org/10.1111/j.1083$\underline{6101.2009 .01494 . x}$

Draper, N., \& Turow, J. (2019). The corporate cultivation of digital resignation. New Media \& Society, 21(8), 1824-1839. https://doi.org/10.1177/1461444819833331

Fiesler, C., \& Hallinan, B. (2018). "We are the product": Public reactions to online data sharing and privacy controversies in the media. Paper presented at the $2018 \mathrm{CHI}$ Conference on Human Factors in Computing Systems, 1-13. https://doi.org/10.1145/3173574.3173627

Hargittai, E., \& Marwick, A. (2016). "What can I really do?" Explaining the privacy paradox with online apathy. International Journal of Communication, 10, 21. 